\title{
Direction of the oblique medial malleolar osteotomy for exposure of the talus
}

\author{
Christiaan J. A. van Bergen • Gabriëlle J. M. Tuijthof • \\ Inger N. Sierevelt • C. Niek van Dijk
}

Received: 22 September 2010 / Published online: 17 December 2010

(C) The Author(s) 2010. This article is published with open access at Springerlink.com

\begin{abstract}
Introduction A medial malleolar osteotomy is often indicated for operative exposure of posteromedial osteochondral defects and fractures of the talus. To obtain a congruent joint surface after refixation, the oblique osteotomy should be directed perpendicularly to the articular surface of the tibia at the intersection between the tibial plafond and medial malleolus. The purpose of this study was to determine this perpendicular direction in relation to the longitudinal tibial axis for use during surgery.

Materials and methods Using anteroposterior mortise radiographs and coronal computed tomography (CT) scans of 46 ankles (45 patients) with an osteochondral lesion of the talus, two observers independently measured the intersection angle between the tibial plafond and medial malleolus. The bisector of this angle indicated the osteotomy perpendicular to the tibial articular surface. This osteotomy was measured relative to the longitudinal tibial axis on radiographs. Intraclass correlation coefficients (ICC) were calculated to assess reliability.

Results The mean osteotomy was $57.2 \pm 3.2^{\circ}$ relative to the tibial plafond on radiographs and $56.5 \pm 2.8$ on CT scans. This osteotomy corresponded to $30.4 \pm 3.7^{\circ}$ relative
\end{abstract}

C. J. A. van Bergen $(\bowtie) \cdot$ G. J. M. Tuijthof · I. N. Sierevelt • C. N. van Dijk

Department of Orthopaedic Surgery,

Orthopaedic Research Center Amsterdam,

Academic Medical Center, University of Amsterdam,

Meibergdreef 9, 1105 AZ, Amsterdam, The Netherlands

e-mail: c.j.vanbergen@amc.nl

\section{G. J. M. Tuijthof}

Department of Biomechanical Engineering,

Faculty of Mechanical, Materials and Maritime Engineering,

Delft University of Technology, Delft, The Netherlands to the longitudinal tibial axis. The intraobserver (ICC, $0.90-0.93$ ) and interobserver (ICC, 0.65-0.91) reliability of these measurements were good to excellent.

Conclusion A medial malleolar osteotomy directed at a mean $30^{\circ}$ relative to the tibial axis enters the joint perpendicularly to the tibial cartilage, and will likely result in a congruent joint surface after reduction.

Keywords Medial malleolus · Osteotomy · Ankle · Radiography $\cdot$ Preoperative planning $\cdot$ Surgical approach

\section{Introduction}

A medial malleolar osteotomy is an established approach for the operative treatment of medial osteochondral defects of the talar dome and fractures of the talar body [1-4]. Ray and Coughlin in 1947 first described a transverse osteotomy [5]. Different techniques have been described since then, including inverted V [6], oblique [7], crescentic [8], stepcut [9], and inverted U osteotomy [10] (Fig. 1).

The oblique osteotomy is an established technique that is used by many surgeons. There are various advantages, including the relatively simple technique, excellent exposure of the talus, preservation of the deltoid ligament, and optimal screw compression [2]. This technique has been shown to provide reproducibly perpendicular access to medial talar lesions treated with osteochondral autograft transfer or metal implants [11-13]. Most surgeons agree that the osteotomy should be aimed at the intersection between the tibial plafond and the articular facet of the medial malleolus [2,14-16]. Failure to exit at this point may lead to limited exposure (too medial), or violate the weight-bearing cartilage on the tibial plafond (too lateral). Concerns of the technique include the difficulty of reduction 
Fig. 1 Anteroposterior (left) and lateral (right) drawings of an ankle, showing the different medial malleolar osteotomy techniques for exposure of the talus as described in the literature. (1) Transverse osteotomy; (2) oblique osteotomy; (3a) stepcut osteotomy; $(3 b)$ modified step-cut osteotomy; (4) crescentic osteotomy; (5) inverted U-osteotomy; (6) inverted V-osteotomy
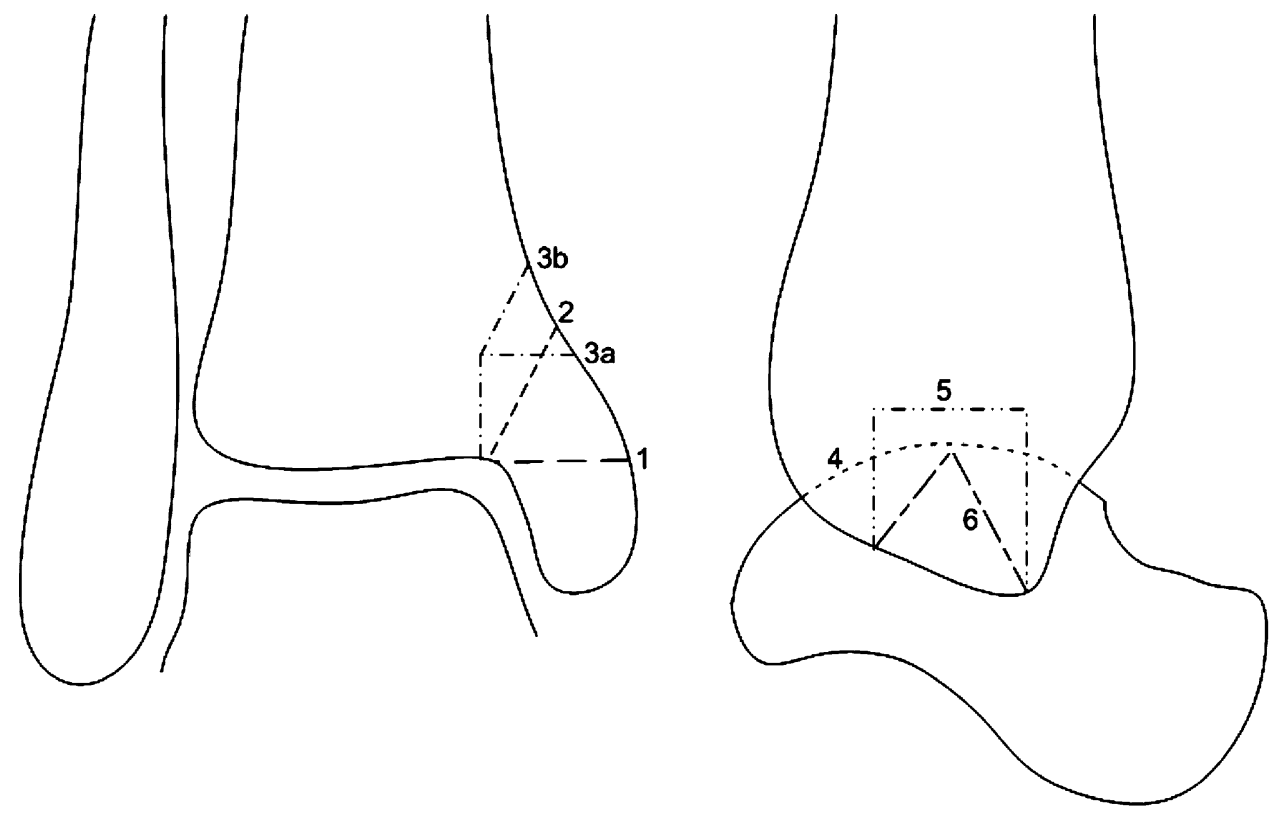

Fig. 2 Schematic drawings of the correct technique in which there is no articular step off after screw fixation through the predrilled screw holes. a After predrilling the screws at $60^{\circ}$ in relation to the tibial axis, the osteotomy is made at $30^{\circ}$ in relation to the tibial axis. A slice of bone is sacrificed when performing the osteotomy due to the saw blade thickness. b Introduction of the compression screws through the predrilled channels will result in a smooth joint surface
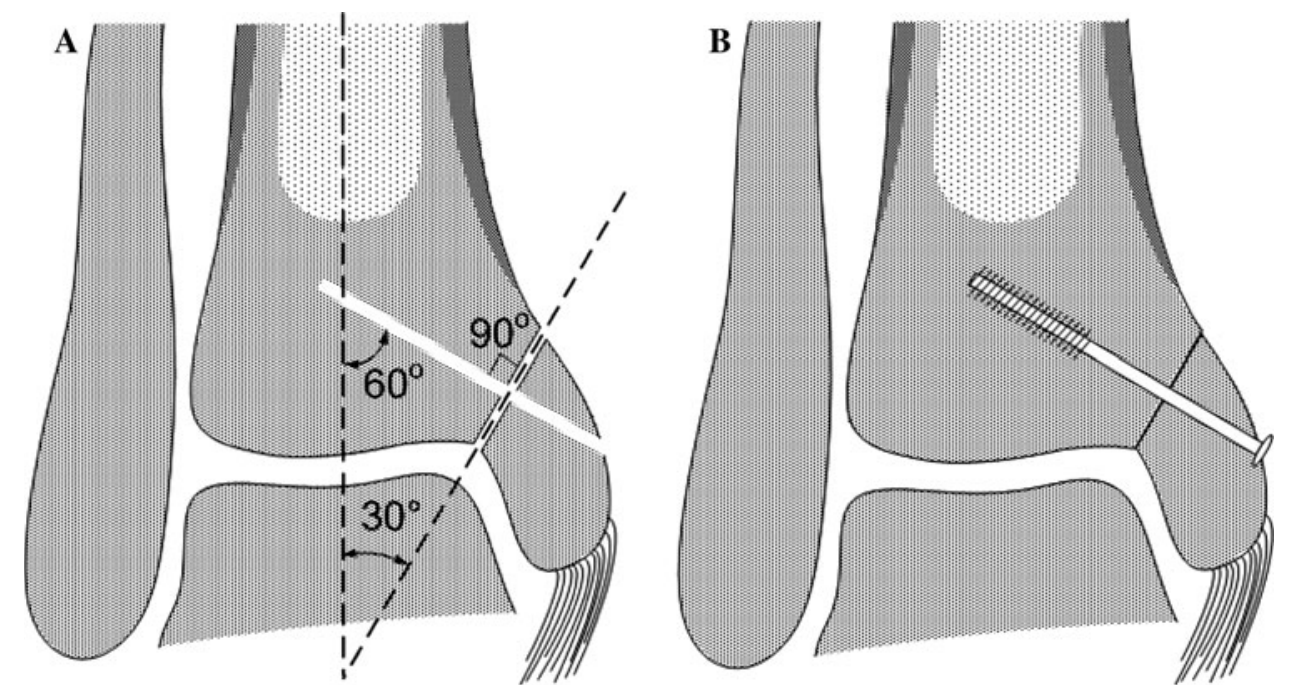

and potential for malunion because apposition may not be colinear with respect to the osteotomy cut $[1,3]$. An incongruent joint surface after fixation could possibly lead to secondary osteoarthritis of the ankle joint $[1,17]$.

In order to obtain a congruent joint surface after fixation, the osteotomy cut is best directed perpendicularly to the articular surface of the tibia (Fig. 2). An osteotomy that is too vertical or too horizontal may result in an incongruent joint surface (i.e., step off) or shortening of the medial malleolus after fixation (Fig. 3). Furthermore, the fixation screws should be directed perpendicularly to the osteotomy plane (Figs. 2, 4).

The longitudinal tibial axis can serve as an intraoperative reference to direct the medial malleolar osteotomy. This axis is commonly used for several orthopedic procedures, including total knee arthroplasty and high tibial osteotomy [18-20].
The objectives of this study were to determine (1) the direction of the oblique medial malleolar osteotomy perpendicular to the articular surface in relation to the longitudinal tibial axis, (2) the interindividual variation in a group of patients, and (3) the reliability of the radiographic methods used.

\section{Materials and methods}

To determine the optimal direction of the osteotomy, we assessed ankle radiographs and computed tomography (CT) scans. Using radiography, we measured the intersection (i.e., angle between the tibial plafond and medial malleolar articular facet), and assessed the tibial axis as a reference to the osteotomy direction. Because the intersection resembles a curved cylinder rather than a two-dimensional corner, CT 
Fig. 3 Schematic drawings of wrong techniques in which the osteotomy angle is too vertical (a) or too horizontal (b), resulting in a step off at the articular surface (small arrows)

Fig. 4 Schematic drawing showing the importance of the direction of fixation screws. The screws should be placed perpendicularly to the osteotomy (see Fig. 2). Even when the osteotomy is performed correctly, a rather vertical (a) or horizontal (b) insertion of the screws may result in an incongruent joint surface after reduction (arrows). Vertical screw placement also causes disruption of the deltoid ligament (a)
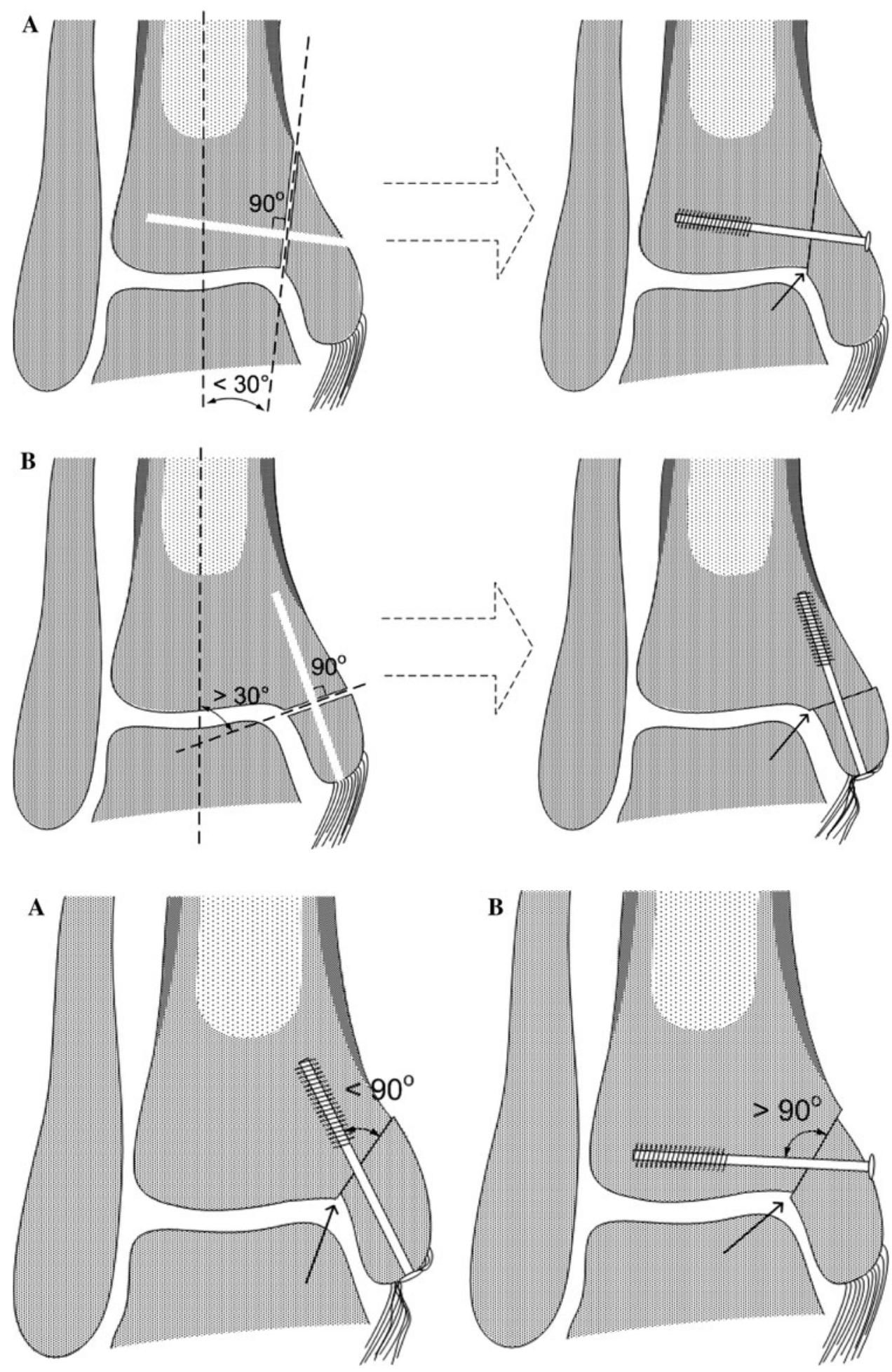

was used as a reference standard to compare with radiography and to assess its intra-articular course.

\section{Patients}

We assessed 46 ankle radiographs and CT scans of 45 consecutive patients (one bilateral) with an osteochondral talar lesion who had visited the outpatient department of our institution from 2006 to 2008. According to Walter and associates, a sample size of 40 was able to detect a minimally acceptable level of reliability of 0.6 and a hoped-for reliability of 0.8 , with $\alpha=0.05$ and a power of $80 \%$ [21]. The patients were derived from two ongoing prospective clinical studies on osteochondral lesions of the talus for 
which approval of the local Medical Ethics Committee was obtained [unpublished]. None of the patients had a history of tibial or ankle fracture. The mean age was $34 \pm 12$ years. There were 30 men and 15 women. Twenty-five lesions were located in the right ankle and 21 in the left. The medial talar dome was affected in 34 ankles, the lateral in eight, the central in two, and both the medial and lateral in two.

\section{Radiography}

Digital weight-bearing anteroposterior mortise view radiographs included the foot distally and approximately half of the lower leg proximally (Fig. 5). The radiographs (4.0 mAs; $57 \mathrm{kV}$ ) were made with the patients' legs in $15^{\circ}$ of internal rotation and the knees extended, with the X-ray beam positioned approximately $1 \mathrm{~m}$ from the ankle and directed horizontally, as previously described [22, 23].

To determine the optimal osteotomy cut, we measured the intersection angle $(\alpha \alpha)$, defined by tangential lines of the tibial plafond and of the medial malleolar articular facet (Fig. 5), using a Picture Archiving and Communication System (PACS, GE Healthcare, Chicago, IL). The bisector of this angle $(\alpha)$, indicating the osteotomy relative to the tibial plafond, was graphically reconstructed. The tibial axis was defined by the line connecting two points in the middle of the proximal and distal tibia [24]. The angle $(\beta)$ between the osteotomy and the longitudinal axis of the tibia was measured (Fig. 5).

All radiographic angles were measured by two independent observers to analyze interobserver reliability. One observer measured the angles a second time in a different order 1 month after the first series to determine intraobserver reliability.

\section{Computed tomography}

Additionally, we assessed 46 multislice helical CT-scans of the same ankles in plantigrade position that included the tibial plafond and talus. Axial CT-scans were obtained with an increment of $0.3 \mathrm{~mm}$ and a thickness of $0.6 \mathrm{~mm}$, and 1-mm coronal slices were reconstructed (Philips MX8000 spiral CT system, Philips Medical Systems, Eindhoven, the Netherlands).

To determine the intra-articular course of the intersection, both observers measured the intersection angle $(\alpha \alpha)$ on the most anterior and the most posterior coronal reconstructions of the tibial plafond, as well as on the middle portion of the tibial plafond, using PACS (Fig. 6). As with the radiographs, the intersection was defined by tangential lines of the tibial plafond and medial malleolar articular facet. The mean of the anterior, middle, and posterior intersection angles was calculated to compare with the radiographic

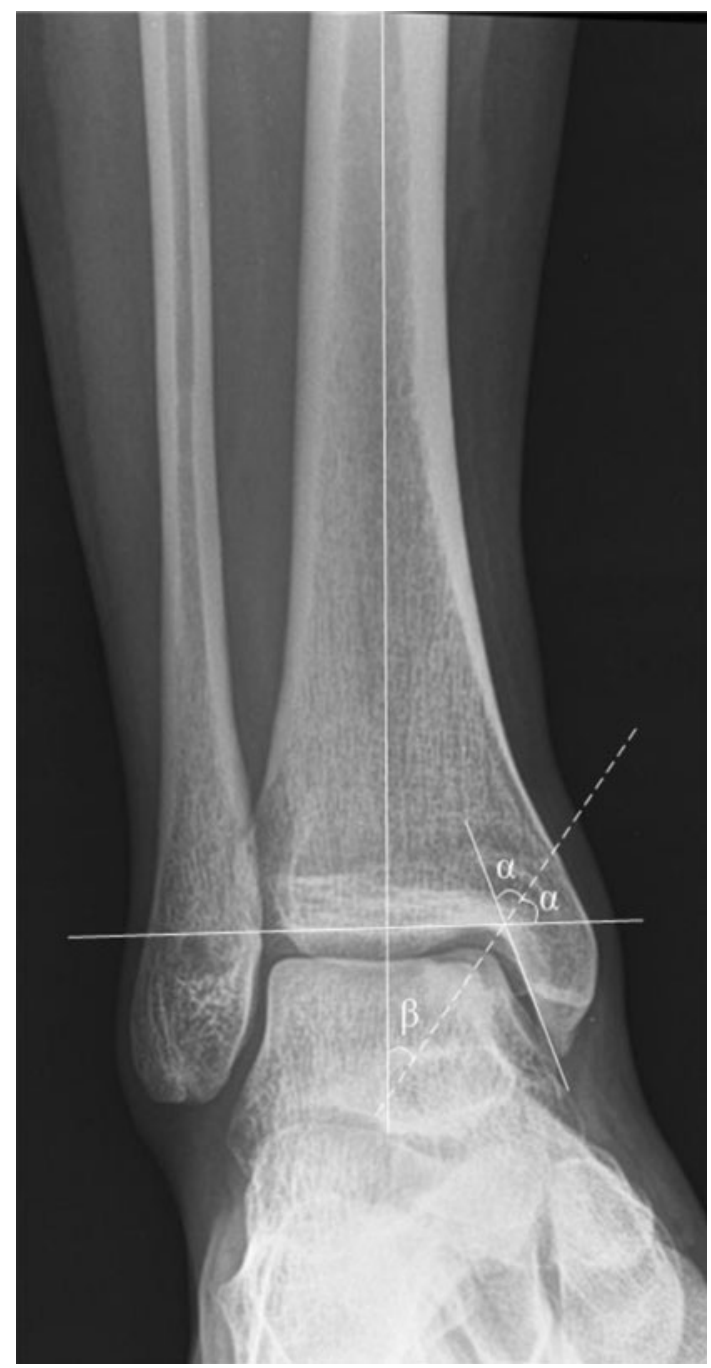

Fig. 5 Anteroposterior mortise radiograph of a right ankle showing the intersection angle $(\alpha \alpha)$ between the tibial plafond and medial malleolus. The bisector of this angle (dashed line) indicates the optimal medial malleolar osteotomy, which is perpendicular to the articular surface. The angle $(\beta)$ between the osteotomy and the longitudinal tibial axis was assessed as a reference to the osteotomy

measurements. The bisector of this angle indicated the osteotomy relative to the tibial plafond.

\section{Statistical analysis}

The values of the angles are presented as mean \pm standard deviation of both observers' first measurement for each measurement made [25]. Intraclass correlation coefficients (ICC) were calculated to determine intra- and interobserver reliability. According to Fleiss, the reliability is considered good if the ICC is $0.40-0.75$ and excellent if the ICC is more than 0.75 [26]. Paired $t$ tests were performed to assess the systematic difference of sequential measurements as well as the systematic difference between corresponding angles on radiography and CT. Agreement between radiography 

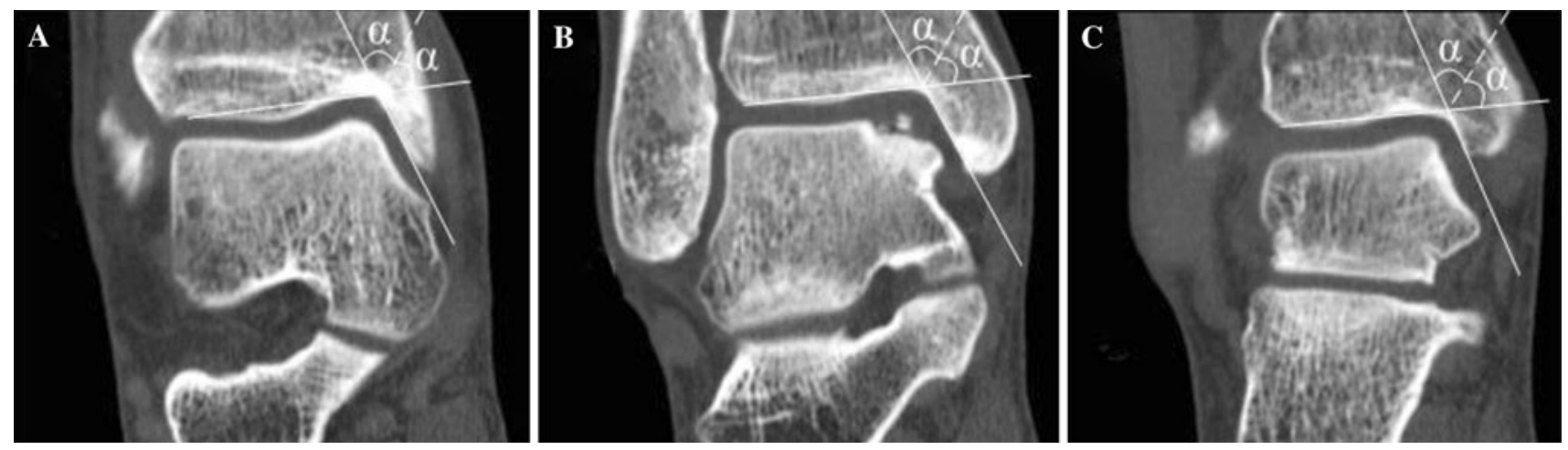

Fig. 6 Coronal computed tomography scans of the same patient as in Fig. 5 showing the most anterior (a), middle (b), and most posterior (c) intersection $(\alpha \alpha)$

and CT was assessed by generating a Bland and Altman plot [25]. We considered an osteotomy angle that differed less than $5.0^{\circ}$ between radiography and $\mathrm{CT}$ as clinically acceptable. Because repeated measurements on the same subject will vary around the true value, measurement error $\left(S_{\mathrm{w}}\right)$ of each parameter (i.e., within-subject standard deviation) was calculated as described by Bland and Altman [27]. Statistics were performed in SPSS version 16.0 (SPSS, Chicago, IL). A $p$ value less than 0.05 was considered significant.

\section{Results}

The results of radiographic measurements are presented in Table 1 . The intersection angle $(\alpha \alpha)$ between the tibial plafond and the articular surface of the medial malleolus was measured $114.5 \pm 6.3^{\circ}$. The osteotomy $(\alpha)$ relative to the tibial plafond (i.e., the bisector of this angle) was $57.2 \pm$ $3.2^{\circ}$. The direction of the proposed osteotomy $(\beta)$ relative to the tibial axis was measured $30.4 \pm 3.7^{\circ}$ (Fig. 7). Forty $(87 \%)$ of 46 ankles were measured within $5.0^{\circ}$ (i.e., $25.4^{\circ}-$ $35.4^{\circ}$ ) of the mean value.
The intraobserver reliability of radiographic measurements was excellent (ICC, 0.90-0.93; $p<0.001$ ). Accordingly, the interobserver reliability was good to excellent (ICC, $0.73-0.82 ; p<0.001$ ). The systematic difference between both measurements of one observer ranged from 0.5 (95\% CI, $0.0-1.0)$ degrees for the osteotomy $(\alpha)$ relative to the tibial plafond to 1.0 (95\% CI, 0.0-1.9) degrees for the intersection $(\alpha \alpha)$. There was no systematical difference between observers for the osteotomy relative to the tibial axis (mean, $0.0^{\circ} ; 95 \% \mathrm{CI},-0.8-0.9$ ). The intraobserver measurement error ranged from 1.2 (osteotomy relative to tibial axis) to $2.4^{\circ}$ (intersection), and the interobserver measurement error ranged from 1.4 to 2.9 (Table 1).

The intersection angle as measured on CT from anterior to posterior ranged from $109.8 \pm 7.8^{\circ}$ at the middle portion of the tibia to $117.3 \pm 5.4^{\circ}$ at the anterior tibia (Table 2). The mean of the anterior, middle, and posterior intersection angles between the tibial plafond and the articular surface of the medial malleolus was $113.0 \pm 5.5^{\circ}$, corresponding to an osteotomy of $56.5 \pm 2.8^{\circ}$ relative to the tibial plafond.

Interobserver reliability of CT was good to excellent (ICC, $0.65-0.91 ; p<0.001$ ). The systematic difference was highest for the posterior intersection (mean, $2.1^{\circ} ; 95 \% \mathrm{CI}$,

Table 1 Results of radiographic measurements

\begin{tabular}{|c|c|c|c|c|c|c|c|c|c|c|}
\hline \multirow[t]{2}{*}{ Angle } & \multirow[t]{2}{*}{ Observer 1} & \multirow{2}{*}{$\begin{array}{l}\text { Observer } 2 \\
\text { (first } \\
\text { measurement) }\end{array}$} & \multirow{2}{*}{$\begin{array}{l}\text { Observer } 2 \\
\text { (second } \\
\text { measurement) }\end{array}$} & \multirow{2}{*}{$\begin{array}{l}\operatorname{Mean}^{\mathrm{a}} \pm \mathrm{SD} \\
\left({ }^{\circ}\right)\end{array}$} & \multicolumn{3}{|c|}{ Intraobserver reliability } & \multicolumn{3}{|c|}{ Interobserver reliability } \\
\hline & & & & & ICC & $\begin{array}{l}\text { Difference } \\
\text { (mean, 95\% CI) }\end{array}$ & $S_{\mathrm{w}}$ & ICC & $\begin{array}{l}\text { Difference } \\
\text { (mean, 95\% CI) }\end{array}$ & $S_{\mathrm{w}}$ \\
\hline Intersection & $113.8 \pm 6.1$ & $115.1 \pm 7.1$ & $116.0 \pm 7.3$ & $114.5 \pm 6.3$ & 0.90 & $1.0(0.0-1.9)$ & 2.4 & 0.82 & $1.3(0.1-2.4)$ & 2.9 \\
\hline $\begin{array}{l}\text { Osteotomy } \\
\angle \text { tibial plafond }\end{array}$ & $56.9 \pm 3.0$ & $57.6 \pm 3.6$ & $58.0 \pm 3.6$ & $57.2 \pm 3.2$ & 0.90 & $0.5(0.0-1.0)$ & 1.2 & 0.82 & $0.6(0.1-1.2)$ & 1.4 \\
\hline $\begin{array}{l}\text { Osteotomy } \\
\angle \text { tibial axis }\end{array}$ & $30.4 \pm 3.4$ & $30.3 \pm 4.5$ & $29.9 \pm 4.5$ & $30.4 \pm 3.7$ & 0.93 & $0.6(0.1-1.0)$ & 1.2 & 0.73 & $0.0(-0.8-0.9)$ & 2.1 \\
\hline
\end{tabular}

The intersection was defined as the angle between tangential lines of the tibial plafond and the articular facet of the medial malleolus. The osteotomy relative to the tibial plafond was defined as the bisector of the intersection angle. All ICCs were statistically significant with $p$ values less than 0.001

ICC Intraclass correlation coefficient, $S D$ standard deviation, $S_{w}$ measurement error, $95 \%$ CI 95\% confidence interval

${ }^{\text {a }}$ Mean of both observers' first measurement 


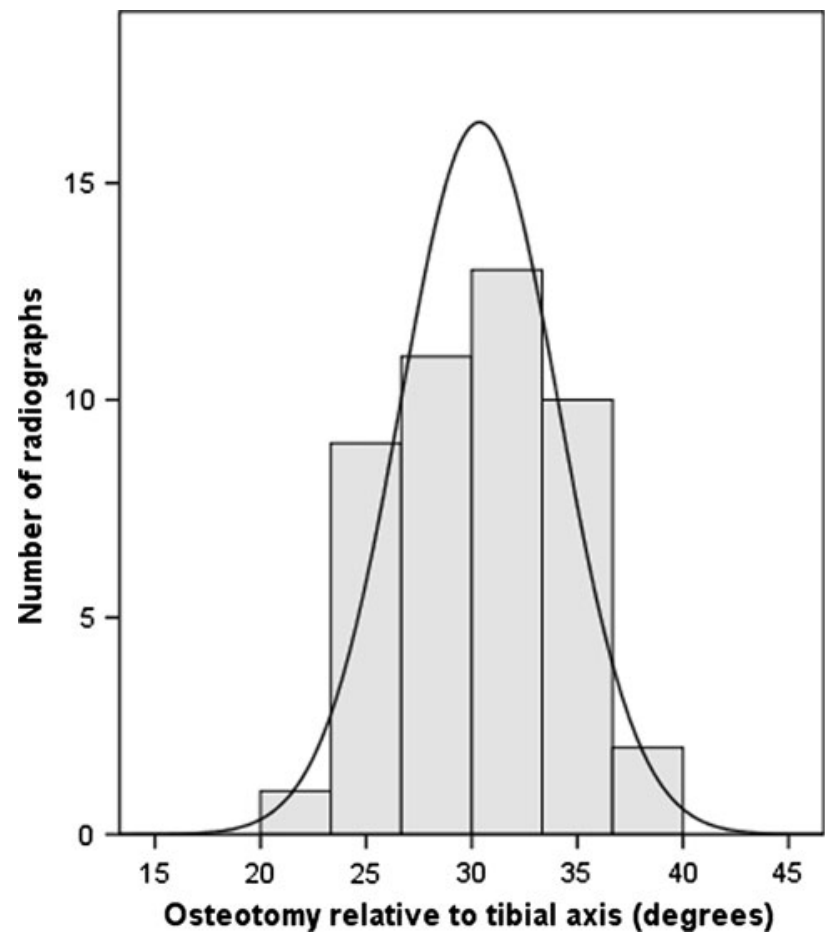

Fig. 7 Histogram representing the distribution of the measured osteotomy relative to the tibial axis. The normal curve indicates a normal distribution with little dispersion $\left(\mathrm{SD}, 3.7^{\circ}\right)$ around a mean of $30^{\circ}$

0.0-4.2). The measurement error ranged from $1.2^{\circ}$ (osteotomy relative to tibial plafond) to $5.2^{\circ}$ (posterior intersection).

There was no statistically significant systematic difference between radiographic and computed tomographic measurements of the mean intersection (mean, $1.4^{\circ} ; 95 \%$ $\mathrm{CI},-0.4-3.2$ ) or the osteotomy (mean, $0.7^{\circ} ; 95 \% \mathrm{CI}$, $-0.2-1.6)$ relative to the tibial plafond. The limits of agreement (i.e., mean $\pm 2 \mathrm{SD}$ of the difference between radiography and CT) of the osteotomy relative to the tibial plafond were $-5.0-5.1^{\circ}$. In 45 of 46 ankles the difference was less than $5.0^{\circ}$ (Fig. 8 ).

\section{Discussion}

In symptomatic osteochondral defects of the talus surgical treatment is indicated when nonoperative treatment has failed [28]. The choice for open versus arthroscopic surgery depends on the location and size of the defect as well as the type of treatment [1]. The preferred technique for primary lesions smaller than $15 \mathrm{~mm}$ is debridement and bone marrow stimulation by means of arthroscopy [29]. For secondary and larger lesions there are various treatment options, including autologous cancellous bone grafting, osteochondral autograft transfer (OATS), autologous chondrocyte implantation (ACI), screw fixation, biodegradable doublelayer implants, metallic implants, and allografts [30]. If the lesion is located on the medial side of the talar dome $(63 \%$ of cases) [31], most of these treatment options require a medial malleolar osteotomy in order to obtain access to the talar dome [1].

The purposes of this study were to determine the direction of the oblique medial malleolar osteotomy relative to the long tibial axis, the interindividual variation, and reliability of the radiographic methods used. The direction of the osteotomy was shown to be $30 \pm 4^{\circ}$ relative to the long tibial axis. This axis is determined intraoperatively by the center of the knee (i.e., tibial tuberosity) proximally and the center of the ankle (i.e., middle of both malleoli) distally. Applying the osteotomy direction of $30^{\circ}$ should minimize the occurrence of a step off of the articular surface after reduction. Radiographic and CT-measurements were reliable, and indicated that the interindividual variation was small in the studied patient group. Since there was little dispersion (Fig. 7), the average $30^{\circ}$ angle may be applicable to a larger group of patients. However, if required, the precise osteotomy can be determined reliably for each individual patient according to the methodology described.

The direction of the oblique medial malleolar osteotomy is addressed in few publications. Several authors suggested a direction of approximately $45^{\circ}$ to the tibial plafond

Table 2 Results of computed tomographic measurements

\begin{tabular}{|c|c|c|c|c|c|c|}
\hline \multirow[t]{2}{*}{ Angle } & \multirow[t]{2}{*}{ Observer 1} & \multirow[t]{2}{*}{ Observer 2} & \multirow[t]{2}{*}{ Mean $\pm \operatorname{SD}\left({ }^{\circ}\right)$} & \multicolumn{3}{|c|}{ Interobserver reliability } \\
\hline & & & & ICC & $\begin{array}{l}\text { Difference } \\
\text { (mean, 95\% CI) }\end{array}$ & $S_{\mathrm{w}}$ \\
\hline Anterior intersection & $116.4 \pm 5.5$ & $118.2 \pm 5.8$ & $117.3 \pm 5.4$ & 0.81 & $1.8(1.0-2.7)$ & 2.5 \\
\hline Middle intersection & $109.8 \pm 7.8$ & $109.8 \pm 8.2$ & $109.8 \pm 7.8$ & 0.91 & $0.1(-1.0-1.1)$ & 2.5 \\
\hline Posterior intersection & $110.9 \pm 9.5$ & $113.0 \pm 7.6$ & $112.0 \pm 7.8$ & 0.65 & $2.1(0.0-4.2)$ & 5.2 \\
\hline Mean intersection & $112.4 \pm 5.4$ & $113.7 \pm 6.0$ & $113.0 \pm 5.5$ & 0.84 & $1.3(0.4-2.2)$ & 2.3 \\
\hline Osteotomy $\angle$ tibial plafond & $56.2 \pm 2.7$ & $56.9 \pm 3.0$ & $56.5 \pm 2.8$ & 0.84 & $0.7(0.2-1.1)$ & 1.2 \\
\hline
\end{tabular}

The mean intersection according to CT was calculated as the mean of the anterior, middle, and posterior intersections. The osteotomy relative to the tibial plafond was defined as the bisector of the mean intersection angle

ICC Intraclass correlation coefficient, $S D$ standard deviation, $S_{\mathrm{w}}$ measurement error, $95 \%$ CI 95\% confidence interval 


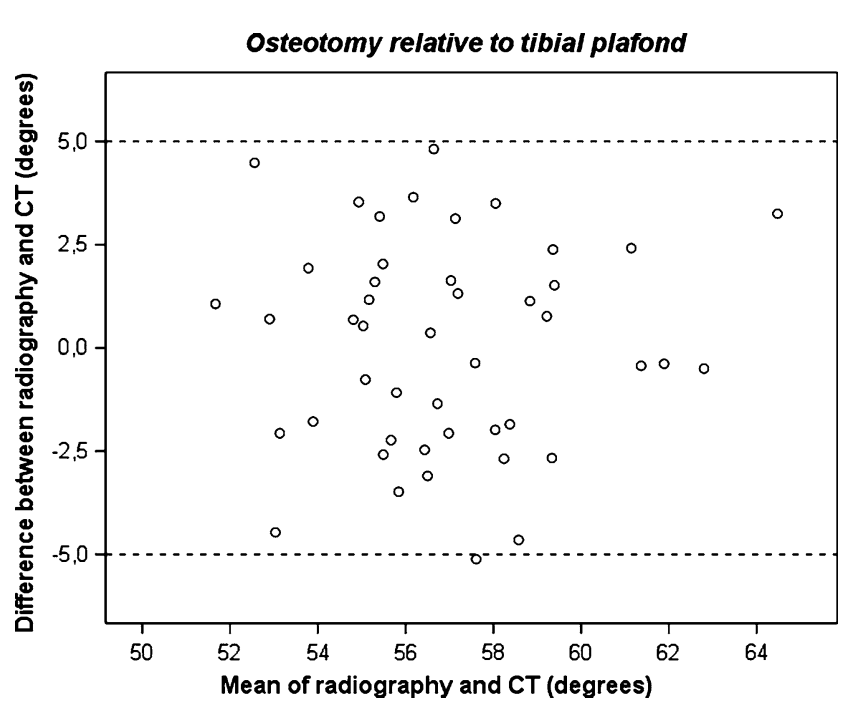

Fig. 8 Bland and Altman plot [25] showing the difference against mean for the osteotomy direction relative to the tibial plafond as measured on radiographs and CT-scans. The clinically acceptable difference between radiography and CT was defined at $5.0^{\circ}$ (dashed lines). One measurement was outside this limit

[15-17], which is more horizontal than the direction found in the present study. Others reported a direction ranging from horizontal [5] to almost vertical [32]. However, none of these directions are based on measurements, and operative methods to achieve the reported angles were not described.

In addition to the direction and location of the osteotomy, the placement of the fixation screws is important. The lag screws are ideally inserted perpendicularly to the osteotomy cut to achieve optimal compression and a congruent joint surface (Fig. 2) [7, 15]. This corresponds to a $60^{\circ}$ angle relative to the long tibial axis. If the screws are inserted either more horizontally or more vertically, an intra-articular step off might result (Fig. 4). The optimal screw direction is thus rather horizontal, which has the additional advantage of preserving the deltoid ligament that originates more distally.

Reports on outcome and complications after oblique medial malleolar osteotomy vary. In a series of 30 patients described by Jarde and colleagues [33], there was no significant difference in outcome between patients treated through a medial malleolar osteotomy, arthrotomy without osteotomy, or arthroscopy. Likewise, Bazaz and Ferkel [14] reported no osteotomy complications in nine patients. Conversely, Gaulrapp et al. [17] found that a medial malleolar osteotomy frequently led to local osteoarthritis and less favorable clinical findings than arthrotomy without osteotomy. Osteoarthritic changes were seen in more than $50 \%$ of 22 patients within 5 years after treatment [17]. Baltzer and Arnold [34] reported malunion in one of 20 cases. In their series, a slight reduction in plantar flexion capacity remained after performing a medial malleolar osteotomy, while the range of motion after using an anterior arthrotomy (23 patients) became equal to the contralateral ankle joint [34]. Unfortunately, it is not possible to relate these outcomes to the direction of the osteotomy used, as the direction was only reported by Gaulrapp et al. who applied $45^{\circ}$.

Although there are different osteotomy techniques of the medial malleolus (Fig. 1), each has disadvantages. A transverse approach [5] is relatively straightforward but exposure of the talar dome may be insufficient because it is covered by the contours of the tibial plafond. Accordingly, with the inverted V [6] and inverted U [10] osteotomies, visualization of the talar dome may be inadequate, and they are contraindicated in patients who have large lesions, limited range of motion, or narrow ankle joints [10]. A crescentic osteotomy [8] has the advantage of conforming to the contour of the talar dome but is made in a horizontal direction, which restricts perpendicular access to the talar dome. A step-cut osteotomy, introduced in 1991 [9] and modified in 2008 [35], provides excellent access but perpendicular fixation of the distal fragment at the articular surface is difficult because the osteotomy enters the joint vertically while the screws are inserted obliquely [36]. The oblique osteotomy is therefore our technique of choice.

There are some limitations of the present study. The measurements utilized a method that relied on two-dimensional measurements of a three-dimensional structure. Comparing the intersection angle at the anterior, middle, and posterior portion of the tibia as measured using CT, the biggest difference was found between the anterior and the middle portions (mean, $7.5^{\circ}$; Table 2). This difference corresponds to a difference in osteotomy direction of $3.8^{\circ}$. Hence, the osteotomy is ideally created in different directions from anteriorly to posteriorly. However, it would be difficult to reproducibly create the osteotomy in this manner because the oscillating saw blade and osteotome are straight. Hence, a straight osteotomy is made in clinical practice. The mean of the anterior, middle, and posterior osteotomy is therefore the best alternative, and this angle corresponded well to the osteotomy determined by radiography. Another limitation is the absence of intraobserver reliability of CT. The radiographic measurements were repeated by an observer but the CT-measurements were not. We considered the radiographic measurements the most important because these provide a clinical guideline, while the CT measurements were made to verify the radiographically measured intersection angle and determine the course of the intersection. Advantages of radiography are the availability, the low costs, and the depiction of approximately half of the tibia, allowing assessment of the tibial axis, which makes it specifically useful for preoperative planning. Although the proximal tibia was not completely visible, the results of our study and those of another study [24] indicate that the described methodology for assessing 
the tibial axis is reliable (Table 1). However, it remains unknown whether this radiographic tibial axis perfectly corresponds to the intraoperative tibial axis, and if the proposed radiographic osteotomy direction corresponds to the clinical direction. We currently perform the osteotomy routinely in the described direction by using the tibial axis as a reference. Clinical studies are indicated to assess whether this angle results in congruent fixation and prevents secondary osteoarthritis.

\section{Conclusion}

The authors present radiographic measurement techniques to determine preoperatively the optimal oblique medial malleolar osteotomy direction. The average osteotomy should be aimed $30^{\circ}$ relative to the tibial axis, in order to exit perpendicularly to the articular surface at the intersection between tibial plafond and articular facet of the medial malleolus.

Conflict of interest The authors declare that they have no conflict of interest.

Open Access This article is distributed under the terms of the Creative Commons Attribution Noncommercial License which permits any noncommercial use, distribution, and reproduction in any medium, provided the original author(s) and source are credited.

\section{References}

1. Navid DO, Myerson MS (2002) Approach alternatives for treatment of osteochondral lesions of the talus. Foot Ankle Clin 7:635649

2. Seil R, Rupp S, Pape D, Dienst M, Kohn D (2001) Approach to open treatment of osteochondral lesions of the talus. Orthopade 30:47-52

3. Thordarson DB (2001) Talar body fractures. Orthop Clin North Am 32:65-77

4. Ziran BH, Abidi NA, Scheel MJ (2001) Medial malleolar osteotomy for exposure of complex talar body fractures. J Orthop Trauma 15:513-518

5. Ray RB, Coughlin EJ (1947) Osteochondritis dissecans of the talus. J Bone Jt Surg 29:697-710

6. O'Farrell TA, Costello BG (1982) Osteochondritis dissecans of the talus. The late results of surgical treatment. J Bone Jt Surg Br 64:494-497

7. Spatt JF, Frank NG, Fox IM (1986) Transchondral fractures of the dome of the talus. J Foot Surg 25:68-72

8. Wallen EA, Fallat LM (1989) Crescentic transmalleolar osteotomy for optimal exposure of the medial talar dome. J Foot Surg 28:389-394

9. Alexander IJ, Watson JT (1991) Step-cut osteotomy of the medial malleolus for exposure of the medial ankle joint space. Foot Ankle $11: 242-243$

10. Oznur A (2001) Medial malleolar window approach for osteochondral lesions of the talus. Foot Ankle Int 22:841-842

11. van Bergen CJ, Zengerink M, Blankevoort L, van Sterkenburg MN, van Oldenrijk J, van Dijk CN (2010) Novel metallic implan- tation technique for osteochondral defects of the medial talar dome. A cadaver study. Acta Orthop 81:495-502

12. Haasper C, Zelle BA, Knobloch K, Jagodzinski M, Citak M, Lotz J, Krettek C, Zeichen J (2008) No mid-term difference in mosaicplasty in previously treated versus previously untreated patients with osteochondral lesions of the talus. Arch Orthop Trauma Surg 128:499-504

13. Hangody L, Kish G, Modis L, Szerb I, Gaspar L, Dioszegi Z, Kendik Z (2001) Mosaicplasty for the treatment of osteochondritis dissecans of the talus: two to seven year results in 36 patients. Foot Ankle Int 22:552-558

14. Bazaz R, Ferkel RD (2004) Treatment of osteochondral lesions of the talus with autologous chondrocyte implantation. Tech Foot Ankle Surg 3:45-52

15. Mendicino RW, Lee MS, Grossman JP, Shromoff PJ (1998) Oblique medial malleolar osteotomy for the management of talar dome lesions. J Foot Ankle Surg 37:516-523

16. Scranton PE Jr, Frey CC, Feder KS (2006) Outcome of osteochondral autograft transplantation for type- $\mathrm{V}$ cystic osteochondral lesions of the talus. J Bone Jt Surg Br 88:614-619

17. Gaulrapp H, Hagena FW, Wasmer G (1996) Die postoperative Bewertung der Osteochondrosis dissecans tali unter besonderer Berücksichtigung der Innenknöchelosteotomie. Z Orthop Ihre Grenzgeb 134:346-353

18. Bae DK, Song SJ, Yoon KH (2009) Closed-wedge high tibial osteotomy using computer-assisted surgery compared to the conventional technique. J Bone Jt Surg Br 91:1164-1171

19. Insall JN, Easley ME (2001) Surgical techniques and instrumentation in total knee arthroplasty. In: Insall JN, Scott WN (eds) Surgery of the knee. Churchill Livingstone, Philadelphia, pp 1553 1620

20. Stiehl JB, Cherveny PM (1996) Femoral rotational alignment using the tibial shaft axis in total knee arthroplasty. Clin Orthop Relat Res (331):47-55

21. Walter SD, Eliasziw M, Donner A (1998) Sample size and optimal designs for reliability studies. Stat Med 17:101-110

22. Lamm BM, Paley D (2004) Deformity correction planning for hindfoot, ankle, and lower limb. Clin Podiatr Med Surg 21:305-326

23. Verhagen RA, Maas M, Dijkgraaf MG, Tol JL, Krips R, van Dijk CN (2005) Prospective study on diagnostic strategies in osteochondral lesions of the talus. Is MRI superior to helical CT? J Bone Jt Surg Br 87:41-46

24. Magerkurth O, Knupp M, Ledermann H, Hintermann B (2006) Evaluation of hindfoot dimensions: a radiological study. Foot Ankle Int 27:612-616

25. Bland JM, Altman DG (1986) Statistical methods for assessing agreement between two methods of clinical measurement. Lancet $1: 307-310$

26. Fleiss JL (1986) The design and analysis of clinical experiments. Wiley, New York

27. Bland JM, Altman DG (1996) Measurement error. BMJ 313:744

28. Tol JL, Struijs PA, Bossuyt PM, Verhagen RA, van Dijk CN (2000) Treatment strategies in osteochondral defects of the talar dome: a systematic review. Foot Ankle Int 21:119-126

29. van Dijk CN, van Bergen CJ (2008) Advancements in ankle arthroscopy. J Am Acad Orthop Surg 16:635-646

30. van Bergen CJ, de Leeuw PA, van Dijk CN (2008) Treatment of osteochondral defects of the talus. Rev Chir Orthop Reparatrice Appar Mot 94:398-408

31. Elias I, Zoga AC, Morrison WB, Besser MP, Schweitzer ME, Raikin SM (2007) Osteochondral lesions of the talus: localization and morphologic data from 424 patients using a novel anatomical grid scheme. Foot Ankle Int 28:154-161

32. O'Loughlin PF, Heyworth BE, Kennedy JG (2010) Current concepts in the diagnosis and treatment of osteochondral lesions of the ankle. Am J Sports Med 38:392-404 
33. Jarde O, Trinquier-Lautard JL, Garate F, De LM, Vives P (2000) Osteochondral lesions of the talar dome: surgical treatment in a series of 30 cases. Rev Chir Orthop Reparatrice Appar Mot 86:608615

34. Baltzer AW, Arnold JP (2005) Bone-cartilage transplantation from the ipsilateral knee for chondral lesions of the talus. Arthroscopy $21: 159-166$
35. Lee KB, Yang HK, Moon ES, Song EK (2008) Modified step-cut medial malleolar osteotomy for osteochondral grafting of the talus. Foot Ankle Int 29:1107-1110

36. Lohrer H (2009) New technique for medial malleolar osteotomy for treatment of osteochondral talar lesions. Foot Ankle Int $30: 285-286$ 